\title{
Safe birth in cultural safety in southern Mexico: a pragmatic non-inferiority cluster- randomised controlled trial
}

Iván Sarmiento ${ }^{1,2^{*}}$ (D) Sergio Paredes-Solís ${ }^{3}$ [D, Abraham de Jesús García ${ }^{3}$ [D, Nadia Maciel Paulino ${ }^{3}$, Felipe René Serrano de los Santos ${ }^{3}$, José Legorreta-Soberanis ${ }^{3} \mathbb{D}$, Germán Zuluaga ${ }^{2} \mathbb{B}$, Anne Cockcroft $^{1} \mathbb{D}$ and Neil Andersson ${ }^{1,3}$ (10)

\begin{abstract}
Background: Available research on the contribution of traditional midwifery to safe motherhood focuses on retraining and redefining traditional midwives, assuming cultural prominence of Western ways. Our objective was to test if supporting traditional midwives on their own terms increases cultural safety (respect of Indigenous traditions) without worsening maternal health outcomes.

Methods: Pragmatic parallel-group cluster-randomised controlled non-inferiority trial in four municipalities in Guerrero State, southern Mexico, with Nahua, Na savi, Me'phaa and Nancue ñomndaa Indigenous groups. The study included all pregnant women in 80 communities and 30 traditional midwives in 40 intervention communities. Between July 2015 and April 2017, traditional midwives and their apprentices received a monthly stipend and support from a trained intercultural broker, and local official health personnel attended a workshop for improving attitudes towards traditional midwifery. Forty communities in two control municipalities continued with usual health services. Trained Indigenous female interviewers administered a baseline and follow-up household survey, interviewing all women who reported pregnancy or childbirth in all involved municipalities since January 2016. Primary outcomes included childbirth and neonatal complications, perinatal deaths, and postnatal complications, and secondary outcomes were traditional childbirth (at home, in vertical position, with traditional midwife and family), access and experience in Western healthcare, food intake, reduction of heavy work, and cost of health care.
\end{abstract}

Results: Among 872 completed pregnancies, women in intervention communities had lower rates of primary outcomes (perinatal deaths or childbirth or neonatal complications) (RD $-0.0695 \% \mathrm{Cl}-0.09$ to -0.02 ) and reported more traditional childbirths (RD $0.1095 \% \mathrm{Cl} 0.02$ to 0.18 ). Among institutional childbirths, women from intervention communities reported more traditional management of placenta (RD $0.3495 \% \mathrm{Cl} 0.21$ to 0.48 ) but also more nontraditional cold-water baths (RD $0.1095 \% \mathrm{Cl} 0.02$ to 0.19 ). Among home-based childbirths, women from intervention communities had fewer postpartum complications (RD $-0.1295 \% \mathrm{Cl}-0.27$ to 0.01 ).

Conclusions: Supporting traditional midwifery increased culturally safe childbirth without worsening health outcomes. The fixed population size restricted our confidence for inference of non-inferiority for mortality outcomes.

\footnotetext{
*Correspondence: ivan.sarmiento@mail.mcgill.ca

1 CIET-Participatory Research at McGill, Faculty of Medicine and Health

Sciences, Department of Family Medicine, McGill University, 5858 Chemin

de la Côte des Neiges 3rd floor, Montreal, QC H3S 1Z1, Canada

Full list of author information is available at the end of the article
}

(C) The Author(s) 2022. Open Access This article is licensed under a Creative Commons Attribution 4.0 International License, which permits use, sharing, adaptation, distribution and reproduction in any medium or format, as long as you give appropriate credit to the original author(s) and the source, provide a link to the Creative Commons licence, and indicate if changes were made. The images or other third party material in this article are included in the article's Creative Commons licence, unless indicated otherwise in a credit line to the material. If material is not included in the article's Creative Commons licence and your intended use is not permitted by statutory regulation or exceeds the permitted use, you will need to obtain permission directly from the copyright holder. To view a copy of this licence, visit http://creativecommons.org/licenses/by/4.0/. The Creative Commons Public Domain Dedication waiver (http://creativeco mmons.org/publicdomain/zero/1.0/) applies to the data made available in this article, unless otherwise stated in a credit line to the data. 
Traditional midwifery could contribute to safer birth among Indigenous communities if, instead of attempting to replace traditional practices, health authorities promoted intercultural dialogue.

Trial registration: Retrospectively registered ISRCTN12397283. Trial status: concluded.

Keywords: Community health worker, Traditional birth attendant, Randomised controlled trial, Equity in access, Aboriginal health, Nahua, Na savi/Mixteco, Méphaa/Tlapaneco, Nancue ñomndaa/Amuzgo

\section{Plain English summary}

In many Indigenous communities, traditional midwives support mothers during pregnancy, childbirth, and some days afterwards. Research involving traditional midwives has focused on training them in Western techniques and redefining their role to support Western care. In Guerrero state, Mexico, Indigenous mothers continue to trust traditional midwives. Almost half of these mothers still prefer traditional childbirths, at home, in the company of their families and following traditional practices. We worked with 30 traditional midwives to see if supporting their practice allowed traditional childbirth without worsening mothers' health. Each traditional midwife received an inexpensive stipend, a scholarship for an apprentice and support from an intercultural broker. The official health personnel participated in a workshop to improve their attitudes towards traditional midwives. We compared 40 communities in two municipalities that received support for traditional midwifery with 40 communities in two municipalities that continued to receive usual services. We interviewed 872 women with childbirth between 2016 and 2017. Mothers in intervention communities suffered fewer complications during childbirth and had fewer complications or deaths of their babies. They had more traditional childbirths and fewer perineal tears or infections across home-based childbirths. Among those who went to Western care, mothers in intervention communities had more traditional management of the placenta but more non-traditional cold-water baths. Supporting traditional midwifery increased traditional childbirth without worsening health outcomes. The small size of participating populations limited our confidence about the size of this difference. Health authorities could promote better health outcomes if they worked with traditional midwives instead of replacing them.

\section{Background}

The contribution of traditional midwives to safe motherhood is the subject of ongoing debate [1-3]. Distinguishing them from Western midwives, traditional midwives have skills based on apprenticeships and "primarily on experience and knowledge acquired informally through the traditions and practices of the communities where they originated" [4]. The dominant approach of Western health services to traditional midwives treats them as unskilled birth attendants. After decades of efforts to retrain them, the current focus is to redefine the role of traditional midwives as auxiliary to or in support of conventional obstetric care $[5,6]$.

Several systematic reviews summarise the impact of retraining traditional midwives or involving them in intervention packages [7-12]. Low to moderate quality evidence shows improvement in "knowledge, attitude, behaviour, and advice" [11]; more referrals to the formal health system [13]; small reductions in perinatal, intrapartum and postnatal mortality [10, 11, 14-19]; statistically significant reduction in maternal morbidity [13] and, with studies of limited size, non-significant reduction in maternal mortality $[10,14,20]$. Several authors have proposed retraining of traditional midwives to do Western childbirths as a cost-effective way to reduce perinatal mortality [21, 22], with evidence less clear for reduction of maternal mortality. Our search of studies involving traditional midwives in Indigenous communities in the Americas between 1946 to 2020 (CINAHL, Scopus, LILACS, MEDLINE, Embase, Google Scholar and 15 additional web engines for grey literature) identified no published randomised controlled trial (RCT) that tested the value of traditional midwifery practices.

In response to a request from local Indigenous communities, researchers at the Centro de Investigación de Enfermedades Tropicales (CIET) at the Universidad Autónoma de Guerrero launched a participatory initiative to address poor maternal health outcomes. In this region, maternal mortality is ten times higher than in the rest of the state [23], which has the highest maternal mortality rate in Mexico [24, 25]. A 2008 survey found Indigenous women in this area preferred home childbirths over hospital childbirths, due to differences between their expectations and the available services [26]. Traditional midwives attended about one half of all childbirths, and women who gave birth attended by traditional midwives reported lower rates of perineal trauma [26]. A 2012 pilot randomised controlled trial found Indigenous women in communities where traditional midwives received support (to pay an apprentice, access a local birthing facility, 
and logistical assistance from a male community health worker) had reduced birth complications compared with their counterparts in control communities. It also suggested other contributions of the intervention, like reduced gender violence [27].

The Safe Birth in Cultural Safety trial tests whether supporting traditional midwives on their own terms results in non-inferior maternal health outcomes while increasing cultural safety around childbirth.

\section{Methods}

This participatory research applies the principles of cultural safety and aims to promote intercultural dialogue between Indigenous and Western health care traditions. The study was part of a bigger initiative to foster intercultural dialogue [27], in which parties with different cultural backgrounds converge to work out solutions around a shared concern of poorer maternal health outcomes $[28,29]$ by respecting Indigenous skills and ways and recognising the needs of scientific evidence [30].

\section{Trial design}

This pragmatic parallel-group cluster-randomised controlled trial tested non-inferiority of a co-designed intervention to support traditional midwifery in two intervention and two control municipalities between 2015 and 2017. Since ethnicity clusters and midwives serve a fixed community base, we used a cluster design. We describe the trial methods fully elsewhere [27]. The study included two levels of clustering: municipalities and communities within municipalities. Participating traditional midwives contributed to the design of the intervention by specifying what support they needed. We measured impact using an administered household survey, interviewing all women who reported pregnancy or childbirth in all involved municipalities during the study period. Trained bilingual Indigenous interviewers administered a baseline survey (February and March 2015) and a follow-up survey using the same procedure and questions (between April and May 2017). Reporting follows the CONSORT Statement [31] and its extensions to cluster randomised trials [32], non-inferiority trials [33] and abstracts [34].

\section{Ethics}

The study conformed to specific ethical principles of research with Indigenous communities [35, 36] and obtained ethical approval from the Ethics Committee of the Centro de Investigación de Enfermedades Tropicales of the Universidad Autónoma de Guerrero (Reference 2013-014) and the Institutional Review Board of the Faculty of Medicine at McGill University (A06-B28-17B). The research team discussed the intervention with the leadership of all participating communities to get their approval to proceed in 2015. We obtained informed consent from Indigenous mothers during data collection and treated all responses from participants as confidential, with no identifying information recorded.

\section{Participants}

Located in the south of Guerrero State in Mexico, the four municipalities are home to four Indigenous groups (Nahua, Na savi/Mixteco, Me'phaa/Tlapaneco and Nancue ñomndaa/Amuzgo). These Indigenous groups have different degrees of acculturation to the Western economy in Mexico, most still living in nuclear families in rural areas or remote small villages. They subsist on small-scale agriculture and migrant labour, typically receiving less than the average wage in the region (approximately $\$ 40$ USD per month) [37]. The study included all Indigenous women in all 80 communities in the four municipalities who gave birth or who became pregnant during the study period (between 2015 and 2017) and their adult family members. There were no exclusions except people who left the municipalities, who were not followed.

The baseline survey identified 30 active traditional midwives (28 women and 2 men) whose communities recognised them based on the positive outcomes of their patients. They were mature adults with decades of practice, spoke almost exclusively Indigenous languages (Me'phaa and Nancue ñomndaa), used traditional techniques learned from a mentor traditional midwife, which included rituals and use of medicinal plants, and had strong connections with the community in which they lived.

\section{Intervention}

The co-designed intervention supported traditional midwifery with four components [27]: (i) Material support: Authentic traditional midwives received a small stipend to increase the time available for their practice and patient care. (ii) Apprentice support: The project paid a scholarship for one apprentice for each midwife. Midwives each appointed their own apprentices and defined their training. Apprentices supported tasks some midwives could no longer perform due to age. (iii) Sensitisation training for staff in the local government health centres: CIET researchers led a workshop in each intervention municipality to present evidence about the role of traditional midwives and the importance of intercultural skills for Western medical practice. (iv) Intercultural health brokers: Community-appointed bilingual young community members received a two-month training $(280 \mathrm{~h})$ as técnicos interculturales de salud. Training covered primary health care, recovery and protection 
of Indigenous culture, and conservation of their territory. After the course, intercultural brokers went back to their communities and supported traditional midwives to increase their reach in the communities and to bridge their interaction with Western health personnel.

Control municipalities continued with usual health services as described in the protocol [27]. Most of the communities in these municipalities also had traditional midwives but they were not supported by the project.

\section{Primary outcomes}

The questionnaire asked each household about household members, pregnancies and births. Women who had given birth in the last year, whether at home or in a health facility, responded to a questionnaire about their pregnancy and childbirth. Primary outcomes for comparison between intervention and non-intervention communities included: birth complications (breach position at birth, excessive bleeding, convulsions and retained placenta); perineal trauma (cut or tear) during childbirth; Caesarean section, and whether the wound became infected; and complications during birth affecting the health of the baby. We intended to ask about postpartum infection, but an error in administration of the questionnaire meant we did not collect this information.

\section{Secondary outcomes}

Secondary outcomes reflected cultural safety. This implies non-disruption of traditional ways of Indigenous groups, which include use of traditional midwives and childbirth at home, in the presence of family. The secondary outcomes included: the number of antenatal checkups by traditional midwives (none vs any); place of birth (home or facility); intended place for future births (home or facility); presence of family members at birth; and use of the traditional vertical position during labour.

Other secondary outcomes reflected interaction between traditional and Western care. We recorded the number of antenatal check-ups in Western care facilities (none vs any and up to four vs five or more). In Mexico, the recommendation is at least five antenatal care checkups. We also recorded timing of the first antenatal care visit (whether during the first trimester or not) and asked if a traditional midwife had advised the pregnant woman to visit a health facility during their pregnancy for routine antenatal care. We categorised attendance at the birth as skilled birth attendance by a traditional midwife or a Western-trained health worker (community health worker, nurse or doctor), non-skilled (for example neighbours or family members), or none.

We asked women who gave birth in institutions about their perinatal management to indicate respect of cultural practices. The women reported if they chose the birth position, availability of translators if required, bathing in cold water, handling of the placenta, retention of amulets, and how respectful they considered their management.

We asked specific questions to explore secondary outcomes of factors that could negatively affect maternal health like heavy work late in pregnancy and food intake during pregnancy. Women also reported the costs of transportation to reach Western health care facilities and if they paid for childbirth, either at home or elsewhere.

\section{Sample size}

Interpretation of non-inferiority trials rests on the upper limit of the effect measure confidence interval [33]. Study power calculation is thus to detect a minimum margin of non-inferiority. We used the ClusterPower package in R [38]: across 80 communities in four municipalities and a between cluster variability of 0.05 , a baseline rate of $30 \%$ for the occurrence of any of the primary outcomes (serious childbirth complications, perinatal deaths and neonatal complications), 420 births in each arm would permit a power of $86 \%$ to exclude a difference in favour of the control group (margin of non-inferiority) of more than $15 \%$ as the upper limit of a $95 \%$ two-sided confidence interval. In the absence of previous studies and estimations of hierarchical variability between municipalities and communities, our calculation recognises the study size needed to establish non-inferiority in the presence of small adverse effects of the intervention and high variability of such effects across clusters. Hierarchical models with more than two levels of clustering would shrink parameters towards the parameters of upper levels [39]. Without previous studies, any assumption on the direction of shrinkage would be speculative.

In practice, the trial included all the available pregnant women in the participating communities for the duration permitted by the existing funding. In the Discussion, we comment on the limitations in interpretation related to sample size.

\section{Randomisation and masking}

An epidemiologist not involved in the fieldwork (NA) generated the allocation sequence and assigned the four municipalities into two parallel groups. The CIET team led by SPS oversaw enrolment of clusters. There was no possibility to conceal intervention status from communities once the intervention began, as supporting traditional midwifery was clearly different from pre-intervention status with unsupported traditional midwifery. 


\section{Statistical methods}

The primary analysis reported outcomes as absolute event rates among intervention and control groups, risk difference (difference of exposed and control rates) with two-sided 95\% confidence intervals (95\%CI) [40]. To establish compatibility of our data with the hypothesis of non-inferior performance of the intervention arm [41], we calculated the significance level at which the confidence interval would exclude parity. We also reported the equivalent odds ratios (OR), a more common measure of effect for binary data [40], to support interpretation. Risk difference is useful for discussion of public health impacts of the intervention and to indicate how the risk of a group would change with the intervention. The interpretation of the OR would be more useful to inform mothers on how supporting traditional midwives could change their chance of having a bad health outcome. To calculate the intra-cluster correlation coefficient (ICC), the opensource software CIETmap 2.2 [42] divided the betweencluster variance by the variance within and between clusters. The primary analysis followed intention-to-treat principles (everyone included in each cluster, per allocation). A cluster-level analysis used the Welch modification of the t-test [40] to compare the mean of the cluster event rates in the intervention and control arms to incorporate the variability across communities. The calculation included the baseline imbalances of the outcomes summarised at the cluster level [43]. The analysis compared cluster-level effects at the community level to account for the maximum variability of both intervention and effect measures.

\section{Secondary analysis}

We established cluster-level differences of primary and secondary outcomes with a multilevel analysis using generalised linear mixed modelling (GLMM) with community as a random effect [44]. The regression models to calculate the measures of effect included differences at baseline. For each model, we reported OR with 95\%CI.

\section{Sensitivity analysis}

The intervention intended to implement all components in all intervention sites. In practice, community security in the face of narco-traffic activities and other factors led to a range of implementation fidelity. To establish the level of fidelity in each community, participating traditional midwives each scored the four intervention components in their communities before the analysis of the final survey (July 2018). The lead author analysed the results of the fidelity scores after the final survey but blind to the results of the survey. We used a classification tree available in rpart in $\mathrm{R}$ to identify baseline characteristics associated with differences in implementation fidelity [45].

A methodological concern in non-inferiority trials using an intention to treat analysis is the potential dilution of the effect measure simply because a participant might have not received the intervention [46]. If the tested treatment was inferior, the observed negative effect in an intention to treat analysis could be smaller than if all patients had adhered to treatment, conversely the study would be more conservative to establish superior effects [33]. We tested consistency across levels of fidelity with three additional analyses [33, 47]. First, we compared outcomes in fully protocol-adherent communities with those in control communities, using GLMM with community as a random effect, adjusted by baseline characteristics. Second, we considered four categories of implementation: (1) communities with good performance in all four intervention components, (2) those with good performance in three components, (3) those with good performance in less than three components and (4) control communities. Finally, we used an instrumental variable analysis to establish the effect among compliers as the ratio of the ITT analysis estimate to the proportion of compliers $[48,49]$.

\section{Missing data}

We report the proportion of missing data for each outcome. We characterised subjects with missing data as far as possible and analysed the effect of missing data using the multiple imputation method in the Amelia II programme in R. We produced ten imputed databases and compared the results with the complete case analysis.

\section{Results}

Figure 1 shows the participant flow of 18,389 women, 6168 of them aged 14-49years in 8051 households in 80 community clusters through the trial. The intervention began in July 2015, with the final survey between April and May 2017, at which time there were 17,907 women (6188 aged 14-49years) in 8174 households. All communities experienced in-migration and out-migration. We added new arrivals to the study but did not follow those leaving the clusters, many of whom migrated to the cities. The final survey included 1177 women who were pregnant during the last year in the intervention and control municipalities; 872 of them reported having completed their pregnancy and 305 were still pregnant (average gestational age 5.9 months, standard deviation 2 months). Nine households reported two pregnant women in the study period.

Table 1 shows 2015 baseline characteristics of included women in the intervention and control arms. Fewer women in the intervention communities 


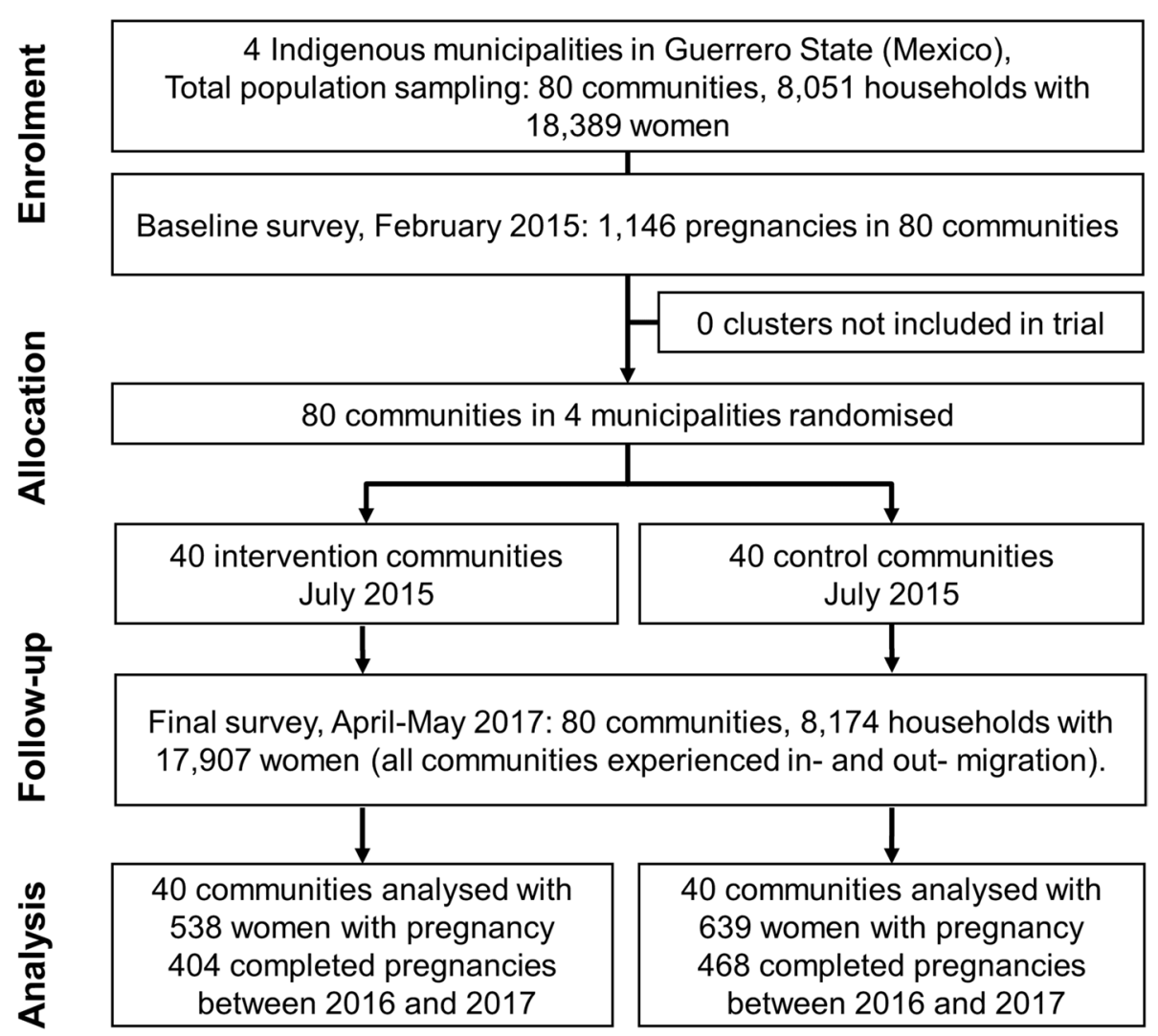

Fig. 1 Flow diagram of progress of clusters and individuals through phases of the randomised trial

used Spanish (they spoke only Indigenous languages). Women in intervention communities were also less likely to have attended school and more likely to be single, to have had their last birth at home, without skilled attendance, and to have made payments related to the birth.

The baseline survey (Table 1) showed very similar rates of perinatal deaths and neonatal complications between intervention and control communities. It suggested more childbirth complications in communities that became the intervention arm, although this was not statistically significant at the $5 \%$ level.

Table 2 shows the demographic characteristics of women in intervention and control communities in 2017. Women in the intervention communities were significantly less likely to have received formal education (RD $-0.2295 \% \mathrm{CI}-0.31$ to -0.13 ) and to speak Spanish (RD $-0.1495 \%$ CI -0.23 to -0.05 ). Missing data of demographic characteristics varied between 1.6 and $3 \%$. We could not detect any identifiable pattern for missing data. The comparison of complete case analysis with imputed datasets did not significantly differ with proportions reported in Table 2.

\section{Outcomes and estimation of the impact}

\section{Primary outcomes}

We analysed event rates of perinatal deaths, mother's report of neonatal complications and serious birth complications between 2016 and 2017 on an intention-totreat basis. Data was compatible at the $95 \%$ level with a lower risk of having one or more of the three primary outcomes (perinatal deaths or childbirth or neonatal complications) in the intervention communities (RD $-0.0695 \% \mathrm{CI}-0.09$ to -0.02 ) (Table 3 ).

Participants reported a total of 26 perinatal deaths in the households. There was a suggestion of reduced risk of perinatal deaths and neonatal complications in intervention communities compared with control communities, but the differences were not significant at the 5\% level (Table 3). The risk of serious childbirth complications was significantly lower in intervention communities (RD $-0.0595 \% \mathrm{CI}-0.08$ to -0.02 ). The analysis excluded parity in favour of the intervention with $95 \%$ confidence for childbirth complications (RD 95\%CI -0.08 to -0.02 ), 90\% confidence for neonatal complications (RD 90\%CI -0.07 to 0.00 ) and $70 \%$ confidence for perinatal mortality (RD 70\%CI -0.02 to 0.00$)$. 
Table 1 Baseline characteristics of intervention and control arms in 2015

\begin{tabular}{|c|c|c|}
\hline \multirow[t]{2}{*}{ Variable } & \multicolumn{2}{|c|}{ Absolut event rates $(n)$} \\
\hline & $\begin{array}{l}\text { Intervention } \\
\text { (cluster } n=40 \text { ) }\end{array}$ & $\begin{array}{l}\text { Control } \\
\text { (cluster } n=40 \text { ) }\end{array}$ \\
\hline Interviewed households $(\mathrm{HH})$ & $0.47(3756 / 8051)$ & $0.53(4295 / 8051)$ \\
\hline HH without tap water & $0.14(518 / 3704)$ & $0.22(928 / 4246)$ \\
\hline \multicolumn{3}{|l|}{ Among 1146 pregnancies } \\
\hline Woman's age ${ }^{a}$ & $25.7(0.4, n=528)$ & $25.9(0.4, n=599)$ \\
\hline Woman speaks Spanish $(p=0.00)^{b}$ & $0.69(355 / 512)$ & $0.86(501 / 580)$ \\
\hline Woman's education above primary $(p=0.02)^{b}$ & $0.45(237 / 529)$ & $0.56(329 / 593)$ \\
\hline Women receives government aid & $0.64(337 / 525)$ & $0.66(388 / 591)$ \\
\hline Woman has health insurance & $0.93(491 / 527)$ & $0.92(548 / 593)$ \\
\hline Woman without a partner $(p=0.05)^{\mathrm{b}}$ & $0.07(35 / 529)$ & $0.10(59 / 596)$ \\
\hline \multicolumn{3}{|l|}{ Among 841 completed pregnancies } \\
\hline Perinatal deaths & $0.03(11 / 386)$ & $0.03(14 / 448)$ \\
\hline Neonatal complications & $0.17(61 / 362)$ & $0.18(76 / 427)$ \\
\hline Childbirth serious complications & $0.20(74 / 366)$ & $0.17(72 / 437)$ \\
\hline Any primary outcome $e^{c}$ & $0.33(128 / 389)$ & $0.31(140 / 452)$ \\
\hline Woman is main decision maker (alone or with partner) & $0.67(248 / 372)$ & $0.74(326 / 439)$ \\
\hline Traditional midwife saw the woman at least once & $0.75(282 / 378)$ & $0.71(313 / 441)$ \\
\hline Woman went to WHC for antenatal care & $0.97(357 / 369)$ & $0.97(422 / 434)$ \\
\hline Gestational age of first recourse to $\mathrm{WHC}^{\mathrm{a}}$ & $3.2(0.1, n=380)$ & $2.8(0.1, n=441)$ \\
\hline Childbirth at home $(p=0.00)^{b}$ & $0.46(171 / 369)$ & $0.26(115 / 438)$ \\
\hline Unattended childbirth $(p=0.05)^{\mathrm{b}}$ & $0.08(28 / 375)$ & $0.04(17 / 439)$ \\
\hline Childbirth with traditional midwife $(p=0.02)^{b}$ & $0.37(137 / 375)$ & $0.23(99 / 439)$ \\
\hline Woman paid for childbirth $(p=0.00)^{b}$ & $0.43(141 / 332)$ & $0.29(121 / 412)$ \\
\hline Company of family during childbirth $(p=0.00)^{b}$ & $0.75(275 / 368)$ & $0.43(189 / 437)$ \\
\hline Traditional childbirth $(p=0.01)^{b}$ & $0.26(98 / 376)$ & $0.13(58 / 441)$ \\
\hline Woman did not suffer violence during pregnancy & $0.97(361 / 372)$ & $0.97(427 / 441)$ \\
\hline Infected wound after childbirth $(p=0.03)^{b}$ & $0.06(21 / 343)$ & $0.03(11 / 422)$ \\
\hline
\end{tabular}

Missing data ranged between 0 and 11.5\%; the highest proportion of missing data was for Woman paid for childbirth (11.5\% or $97 / 841$ completed pregnancies) and Infected wound after childbirth ( $9 \%$ or $76 / 841$ )

$\mathrm{HH}$ Household, WHC Western health care facility

${ }^{a}$ Average (SD, n)

${ }^{\mathrm{b}}$ cluster-level t-test

${ }^{c}$ childbirth or neonatal complication or perinatal death

${ }^{\mathrm{d}}$ Medical doctor, nurse or traditional midwife vs casual or unattended childbirth

Adjusted for baseline differences of the outcomes, a GLMM with intervention as a fixed effect and community as a random effect showed very similar measures of effect as the unadjusted analysis (shown in Table 3).

Overall, women in intervention communities had almost identical rates of postpartum perineal trauma or wound infection (Table 3). However, among home childbirths, women in intervention communities had a lower risk of perineal trauma or wound infection compared with women in control communities, although this was not significant at $5 \%$ level.

Missing data of primary outcomes varied from $0.6 \%$ (5/854 for childbirth serious complications) to $3.7 \%$
(32/854 for Caesarean section). We could not identify particular patterns for missing data as the numbers of missing data subjects were sparse. Comparison of imputed datasets and complete case analysis did not identify significant divergences, but showed increased uncertainty around the difference for the number of Caesarean sections.

\section{Secondary outcomes}

Analysis of secondary outcomes confirmed higher rates of traditional birth (at home, in company of family, with traditional midwife and mainly in vertical position) in intervention communities (RD $0.1095 \% \mathrm{CI} 0.02$ to 0.18 ) 
Table 2 Demographic characteristics of intervention and control arms in 2017

\begin{tabular}{|c|c|c|}
\hline \multirow[t]{2}{*}{ Variable } & \multicolumn{2}{|c|}{ Absolut event rate (n) } \\
\hline & $\begin{array}{l}\text { Intervention } \\
\text { (cluster } n=40 \text { ) }\end{array}$ & $\begin{array}{l}\text { Control } \\
\text { (cluster } n=40 \text { ) }\end{array}$ \\
\hline Interviewed households $(\mathrm{HH})$ & $0.47(3836 / 8174)$ & $0.53(4338 / 8174)$ \\
\hline Total population & $0.47(16,321 / 35091)$ & $0.54(18,770 / 35091)$ \\
\hline People in each $\mathrm{HH}^{*}$ & $4.3(2.0, n=3836)$ & $4.3(2.0, n=4338)$ \\
\hline $\mathrm{HH}$ without tap water & $0.88(3351 / 3807)$ & $0.81(3518 / 4321)$ \\
\hline Women parity* & $2.0(1.7, n=530)$ & $1.9(1.7, n=628)$ \\
\hline Women age* & $25.5(6.6, n=530)$ & $25.6(6.6, n=627)$ \\
\hline Women education above primary $(p=0.00)^{a}$ & $0.47(246 / 529)$ & $0.60(372 / 622)$ \\
\hline Woman speaks Spanish $(p=0.00)^{\mathrm{a}}$ & $0.68(353 / 521)$ & $0.90(556 / 621)$ \\
\hline Woman without a partner & $0.07(37 / 527)$ & $0.07(45 / 623)$ \\
\hline Women receives government aid & $0.58(304 / 524)$ & $0.53(329 / 620)$ \\
\hline Woman has health insurance & $0.94(497 / 529)$ & $0.94(586 / 624)$ \\
\hline
\end{tabular}

${ }^{*}$ Average (standard deviation SD, $\mathrm{n}$ )

a cluster-level t-test

Table 3 Effect measures for the primary outcomes (intention to treat analysis)

\begin{tabular}{|c|c|c|c|c|c|}
\hline \multirow[t]{2}{*}{ Variable } & \multicolumn{2}{|c|}{$\begin{array}{l}\text { Absolut event rate } \\
\text { (n) } \\
\text { (cluster } n=40)\end{array}$} & \multirow[t]{2}{*}{$\begin{array}{l}\mathrm{RD} \\
95 \% \mathrm{Cl}^{\mathrm{a}}\end{array}$} & \multirow[t]{2}{*}{$\begin{array}{l}\text { OR } \\
95 \% \mathrm{Cl}^{\mathrm{b}}\end{array}$} & \multirow[t]{2}{*}{ ICC } \\
\hline & Intervention & Control & & & \\
\hline Any primary outcomes ${ }^{c}$ & $\begin{array}{l}0.12 \\
(50 / 404)\end{array}$ & $\begin{array}{l}0.18 \\
(85 / 468)\end{array}$ & $\begin{array}{l}-0.06 \\
-0.09 \text { to }-0.02\end{array}$ & $\begin{array}{l}0.63 \\
0.42 \text { to } 0.95\end{array}$ & 0.03 \\
\hline Perinatal deaths 2016 and 2017 & $\begin{array}{l}0.02 \\
(10 / 404)\end{array}$ & $\begin{array}{l}0.03 \\
(16 / 468)\end{array}$ & $\begin{array}{l}-0.01 \\
-0.04 \text { to } 0.02\end{array}$ & $\begin{array}{l}0.73 \\
0.31 \text { to } 1.75\end{array}$ & 0.04 \\
\hline Neonatal complications ${ }^{d}$ & $\begin{array}{l}0.06 \\
(23 / 389)\end{array}$ & $\begin{array}{l}0.07 \\
(39 / 456)\end{array}$ & $\begin{array}{l}-0.04 \\
-0.08 \text { to } 0.01\end{array}$ & $\begin{array}{l}0.59 \\
0.30 \text { to } 1.18\end{array}$ & 0.05 \\
\hline Childbirth serious problems & $\begin{array}{l}0.05 \\
(19 / 393)\end{array}$ & $\begin{array}{l}0.08 \\
(35 / 456)\end{array}$ & $\begin{array}{l}-0.05 \\
-0.08 \text { to }-0.02\end{array}$ & $\begin{array}{l}0.35 \\
0.14 \text { to } 0.92\end{array}$ & 0.00 \\
\hline Caesarean section & $\begin{array}{l}0.13 \\
(50 / 381)\end{array}$ & $\begin{array}{l}0.15 \\
(66 / 441)\end{array}$ & $\begin{array}{l}-0.03 \\
-0.10 \text { to } 0.04\end{array}$ & $\begin{array}{l}0.78 \\
0.47 \text { to } 1.31\end{array}$ & 0.11 \\
\hline Perineal trauma or wound infection & $\begin{array}{l}0.21 \\
(81 / 389)\end{array}$ & $\begin{array}{l}0.21 \\
(94 / 455)\end{array}$ & $\begin{array}{l}0.01 \\
-0.07 \text { to } 0.08\end{array}$ & $\begin{array}{l}1.06 \\
0.70 \text { to } 1.61\end{array}$ & 0.07 \\
\hline $\begin{array}{l}\text { Perineal trauma or wound infection in home } \\
\text { childbirths }\end{array}$ & $\begin{array}{l}0.11 \\
(17 / 156)\end{array}$ & $\begin{array}{l}0.24 \\
(27 / 116)\end{array}$ & $\begin{array}{l}-0.12 \\
-0.27 \text { to } 0.01\end{array}$ & $\begin{array}{l}0.40 \\
0.15 \text { to } 1.05\end{array}$ & 0.18 \\
\hline
\end{tabular}

$R D$ risk difference, $O R$ odds ratio, $I C C$ Intra-cluster correlation coefficient

${ }^{\text {a }}$ Baseline-adjusted cluster-level analysis using t-test as presented by Campbell, 2014

${ }^{\mathrm{b}} \mathrm{OR}$ and confidence intervals calculated with a GLMM using Ime4 package in $\mathrm{R}$

' childbirth or neonatal complication or perinatal death

d 854 women with completed pregnancies reported on childbirth or neonatal complications, and 18 women with completed pregnancies reported only on perinatal deaths

(Table 4). More births were attended by traditional midwives in intervention than in control communities (RD $0.1495 \% 0.03$ to 0.25 ) (Table 4). In both intervention and control communities, traditional midwives saw more than $70 \%$ of all women during pregnancy, and almost $70 \%$ of those who gave birth in Western healthcare facilities (Table 4).
Women in intervention communities were also significantly less likely to say they intended to have future hospital-based childbirth (RD $-0.1795 \% \mathrm{CI}-0.26$ to -0.07 ) (Table 4). This preference was associated with the place of the last childbirth. Within intervention communities, a woman who gave birth with a traditional midwife was less likely to desire a future institutional childbirth (31.4\% 
Table 4 Secondary outcomes (intention to treat analysis)

\begin{tabular}{|c|c|c|c|c|}
\hline \multirow[t]{2}{*}{ Secondary outcomes } & \multicolumn{2}{|c|}{$\begin{array}{l}\text { Absolute event rate } \\
\text { (n) } \\
\text { (cluster } n=40 \text { ) }\end{array}$} & \multirow[t]{2}{*}{$\begin{array}{l}\text { RD } \\
95 \% \mathrm{Cla}^{\mathrm{a}}\end{array}$} & \multirow[t]{2}{*}{$\begin{array}{l}\text { OR } \\
95 \% \mathrm{Cl}^{\mathrm{b}}\end{array}$} \\
\hline & Intervention & Control & & \\
\hline \multicolumn{5}{|l|}{ Traditional childbirth } \\
\hline Total traditional childbirths ${ }^{c d}$ & $\begin{array}{l}0.19 \\
(75 / 394)\end{array}$ & $\begin{array}{l}0.11 \\
(48 / 457)\end{array}$ & $\begin{array}{l}0.10 \\
0.02 \text { to } 0.18\end{array}$ & $\begin{array}{l}2.95 \\
1.27 \text { to } 6.84\end{array}$ \\
\hline Childbirth with traditional midwife ${ }^{c}$ & $\begin{array}{l}0.31 \\
(123 / 392)\end{array}$ & $\begin{array}{l}0.20 \\
(90 / 456)\end{array}$ & $\begin{array}{l}0.14 \\
0.03 \text { to } 0.25\end{array}$ & $\begin{array}{l}2.49 \\
2.20 \text { to } 5.17\end{array}$ \\
\hline Childbirth at home & $\begin{array}{l}0.40 \\
(158 / 394)\end{array}$ & $\begin{array}{l}0.25 \\
(114 / 454)\end{array}$ & $\begin{array}{l}0.04 \\
-0.11 \text { to } 0.19\end{array}$ & $\begin{array}{l}1.13 \\
0.52 \text { to } 2.45\end{array}$ \\
\hline Vertical childbirth ${ }^{c}$ & $\begin{array}{l}0.29 \\
(111 / 388)\end{array}$ & $\begin{array}{l}0.18 \\
(81 / 454)\end{array}$ & $\begin{array}{l}0.12 \\
0.03 \text { to } 0.22\end{array}$ & $\begin{array}{l}2.38 \\
1.26 \text { to } 4.47\end{array}$ \\
\hline Company of family during childbirth ${ }^{c}$ & $\begin{array}{l}0.63 \\
(244 / 390)\end{array}$ & $\begin{array}{l}0.46 \\
(205 / 450)\end{array}$ & $\begin{array}{l}0.17 \\
0.06 \text { to } 0.28\end{array}$ & $\begin{array}{l}2.21 \\
1.41 \text { to } 3.48\end{array}$ \\
\hline Intention of future childbirth at $\mathrm{WHC}^{\mathrm{c}}$ & $\begin{array}{l}0.64 \\
(244 / 379)\end{array}$ & $\begin{array}{l}0.80 \\
(362 / 453)\end{array}$ & $\begin{array}{l}-0.17 \\
-0.26 \text { to }-0.07\end{array}$ & $\begin{array}{l}0.37 \\
0.21 \text { to } 0.66\end{array}$ \\
\hline Traditional midwife saw the woman at least once & $\begin{array}{l}0.78 \\
(406 / 523)\end{array}$ & $\begin{array}{l}0.73 \\
(458 / 624)\end{array}$ & $\begin{array}{l}0.06 \\
-0.02 \text { to } 0.14\end{array}$ & $\begin{array}{l}1.47 \\
0.93 \text { to } 2.33\end{array}$ \\
\hline \multicolumn{5}{|l|}{ Access to health care services } \\
\hline Woman went to WHC for antenatal care & $\begin{array}{l}0.95 \\
(497 / 523)\end{array}$ & $\begin{array}{l}0.96 \\
(590 / 618)\end{array}$ & $\begin{array}{l}0.00 \\
-0.04 \text { to } 0.03\end{array}$ & $\begin{array}{l}1.04 \\
0.49 \text { to } 2.22\end{array}$ \\
\hline At least 5 check-ups with WHC & $\begin{array}{l}0.71 \\
(264 / 376)\end{array}$ & $\begin{array}{l}0.74 \\
(323 / 437)\end{array}$ & $\begin{array}{l}-0.03 \\
-0.12 \text { to } 0.05\end{array}$ & $\begin{array}{l}0.88 \\
0.57 \text { to } 1.36\end{array}$ \\
\hline Gestational age of first recourse to $\mathrm{WHC}^{*}$ & $\begin{array}{l}3.0 \\
(0.3, n=392)\end{array}$ & $\begin{array}{l}3.0 \\
(0.1, n=459)\end{array}$ & & \\
\hline Traditional midwife advised visiting WHC & $\begin{array}{l}0.79 \\
(246 / 310)\end{array}$ & $\begin{array}{l}0.82 \\
(292 / 356)\end{array}$ & $\begin{array}{l}-0.06 \\
-0.19 \text { to } 0.07\end{array}$ & $\begin{array}{l}0.87 \\
0.55 \text { to } 1.37\end{array}$ \\
\hline Childbirth with Western provider ${ }^{e}$ & $\begin{array}{l}0.61 \\
(238 / 392)\end{array}$ & $\begin{array}{l}0.75 \\
(340 / 456)\end{array}$ & $\begin{array}{l}-0.01 \\
-0.16 \text { to } 0.11\end{array}$ & $\begin{array}{l}0.88 \\
0.39 \text { to } 1.99\end{array}$ \\
\hline $\begin{array}{l}\text { Antenatal care with traditional midwife and childbirth with } \\
\text { Western provider }\end{array}$ & $\begin{array}{l}0.68 \\
(161 / 237)\end{array}$ & $\begin{array}{l}0.70 \\
(237 / 340)\end{array}$ & $\begin{array}{l}-0.02 \\
-0.12 \text { to } 0.08\end{array}$ & $\begin{array}{l}1.09 \\
0.66 \text { to } 1.82\end{array}$ \\
\hline Unattended childbirths & $\begin{array}{l}0.08 \\
(31 / 392)\end{array}$ & $\begin{array}{l}0.06 \\
(26 / 456)\end{array}$ & $\begin{array}{l}0.02 \\
-0.02 \text { to } 0.06\end{array}$ & $\begin{array}{l}1.58 \\
0.74 \text { to } 3.35\end{array}$ \\
\hline Paid for childbirth & $\begin{array}{l}0.38 \\
(138 / 367)\end{array}$ & $\begin{array}{l}0.24 \\
(106 / 443)\end{array}$ & $\begin{array}{l}0.12 \\
-0.02 \text { to } 0.25\end{array}$ & $\begin{array}{l}1.83 \\
0.95 \text { to } 3.52\end{array}$ \\
\hline Paid for childbirth with Western provider ${ }^{c}$ & $\begin{array}{l}0.28 \\
(62 / 225)\end{array}$ & $\begin{array}{l}0.13 \\
(44 / 331)\end{array}$ & $\begin{array}{l}0.14 \\
0.04 \text { to } 0.24\end{array}$ & $\begin{array}{l}2.67 \\
1.26 \text { to } 5.66\end{array}$ \\
\hline Average cost of childbirth (USD)* & $\begin{array}{l}68.6 \\
(28.7, n=138)\end{array}$ & $\begin{array}{l}84.3 \\
(14.7, n=106)\end{array}$ & & \\
\hline \multicolumn{5}{|l|}{ Childbirth in Western facility } \\
\hline The woman chose childbirth position & $\begin{array}{l}0.60 \\
(139 / 231)\end{array}$ & $\begin{array}{l}0.61 \\
(205 / 336)\end{array}$ & $\begin{array}{l}-0.08 \\
-0.24 \text { to } 0.08\end{array}$ & $\begin{array}{l}0.97 \\
0.57 \text { to } 1.66\end{array}$ \\
\hline Translator during childbirth (if needed) & $\begin{array}{l}0.42 \\
(63 / 151)\end{array}$ & $\begin{array}{l}0.32 \\
(83 / 262)\end{array}$ & $\begin{array}{l}0.04 \\
-0.09 \text { to } 0.18\end{array}$ & $\begin{array}{l}1.59 \\
0.94 \text { to } 2.69\end{array}$ \\
\hline Woman had to bathe with cold water ${ }^{c}$ & $\begin{array}{l}0.60 \\
(138 / 231)\end{array}$ & $\begin{array}{l}0.45 \\
(154 / 341)\end{array}$ & $\begin{array}{l}0.10 \\
0.02 \text { to } 0.19\end{array}$ & $\begin{array}{l}1.72 \\
0.99 \text { to } 3.00\end{array}$ \\
\hline The woman received the placenta ${ }^{c}$ & $\begin{array}{l}0.56 \\
(130 / 232)\end{array}$ & $\begin{array}{l}0.21 \\
(69 / 335)\end{array}$ & $\begin{array}{l}0.34 \\
0.21 \text { to } 0.48\end{array}$ & $\begin{array}{l}6.15 \\
3.24 \text { to } 11.7\end{array}$ \\
\hline Retention of amulets & $\begin{array}{l}0.30 \\
(68 / 229)\end{array}$ & $\begin{array}{l}0.27 \\
(89 / 335)\end{array}$ & $\begin{array}{l}0.03 \\
-0.09 \text { to } 0.15\end{array}$ & $\begin{array}{l}1.18 \\
0.67 \text { to } 2.06\end{array}$ \\
\hline The woman felt she was treated with respect & $\begin{array}{l}0.89 \\
(210 / 237)\end{array}$ & $\begin{array}{l}0.92 \\
(312 / 338)\end{array}$ & $\begin{array}{l}-0.04 \\
-0.12 \text { to } 0.03\end{array}$ & $\begin{array}{l}0.67 \\
0.31 \text { to } 1.42\end{array}$ \\
\hline
\end{tabular}


Table 4 (continued)

\begin{tabular}{|c|c|}
\hline Secondary outcomes & $\begin{array}{l}\text { Absolute } \\
\text { (n) } \\
\text { (cluster } n\end{array}$ \\
\hline & Intervent \\
\hline \multicolumn{2}{|l|}{ Behaviours } \\
\hline Woman eats same or more than usual during pregnancy & $\begin{array}{l}0.22 \\
(85 / 394)\end{array}$ \\
\hline Woman works less than usual during pregnancy & $\begin{array}{l}0.37 \\
(144 / 394)\end{array}$ \\
\hline \multicolumn{2}{|l|}{ WHC Western health care facility, $R D$ risk difference, $O R$ odds ratio } \\
\hline \multicolumn{2}{|c|}{ a Baseline-adjusted cluster-level analysis using t-test as presented by Campbell, 2014} \\
\hline \multicolumn{2}{|l|}{${ }^{\mathrm{b}} \mathrm{OR}$ and confidence intervals calculated with a GLMM using Ime4 package in $\mathrm{R}$} \\
\hline \multicolumn{2}{|l|}{ ' significant differences at the $5 \%$ level } \\
\hline \multicolumn{2}{|l|}{ d at home, with traditional midwife and family and in preferred vertical position } \\
\hline \multicolumn{2}{|l|}{ e doctor, nurse or health promotor } \\
\hline \multicolumn{2}{|l|}{ *Average (standard deviation SD, $\mathrm{n}$ ) } \\
\hline
\end{tabular}

or 38/121) compared with a woman who had institutional childbirth $(80.5 \%$ or $206 / 256$, OR $0.1395 \%$ CI 0.06 to 0.21 ). Among those who gave birth in Western health facilities, women in intervention communities were significantly more likely to receive the placenta after childbirth, as required by custom, than women in the control arm (RD 0.34 95\% 0.21-0.48) (Table 4). There were no other positive differences in the experience in health care facilities of women in intervention communities, and they were more likely to report being forced to bath with cold water after childbirth (RD $0.1095 \% 0.02$ to 0.19 ) (Table 4). For childbirths with a Western provider, more intervention women had to pay than did control women (RD 0.14 95\%CI 0.04 to 0.24).

\section{Sensitivity analysis}

The traditional midwives reported that $13 / 40$ communities performed well across the four intervention components, 9/40 performed well in three components, and $18 / 40$ performed well in less than three components (Supplementary material 1). The main concerns of traditional midwives regarding implementation were the commitment of some apprentices and the lack of continuity of five intercultural brokers. Communities with a smaller number of births at home and remote communities with less Indigenous language speakers and communities with a Western health facility had lower intervention fidelity. Per-protocol analysis compared the communities with the highest level of intervention fidelity (29.4\% or $119 / 404$ childbirths) with the control communities. Women in protocol-adherent communities showed higher rates of traditional births than women in control communities (RD 0.23 95\%CI 0.09 to 0.38) (Table 5). These communities also had fewer unattended childbirths than did control communities (difference not significant at the $5 \%$ level, Table 5). Most of the unattended childbirths observed in the intervention arm happened in communities with less than three intervention components satisfactorily implemented $(5.1 \%(10 / 197)$ compared with 10.8 (21/195), RD $-0.0695 \% \mathrm{CI}-0.11$ to -0.01$)$.

The measures of effect for primary outcomes confirmed the results from the intention to treat analysis with wider confidence intervals, due to a reduced number of participants involved in the calculation. When compared with control communities (Table 5), protocol-adherent communities had non significantly lower perinatal mortality, neonatal complications and significantly lower childbirth complications (RD -0.05 95\%CI -0.08 to -0.02 ).

Supplementary material 2 shows a comparison of groups as treated using GLMM. Serious complications were significantly lower in the communities with fair or good performance compared with control communities (RD $-0.0595 \% \mathrm{CI}-0.08$ to -0.01 ) or compared with control and poor performance communities together (RD $-0.0495 \%$ CI -0.08 to -0.01 ) (Table 5).

The instrumental variable analysis confirmed the average protective effect among compliers although with increased confidence intervals for perinatal deaths and neonatal complications (Table 5). For serious childbirth complications, this analysis also confirmed exclusion of inferior performance of the intervention among compliers (RD $-0.0995 \% \mathrm{CI}-0.18$ to 0.00$)$.

\section{Discussion}

The Safe Birth in Cultural Safety trial in Guerrero found lower perinatal deaths, neonatal complications and serious childbirth complications after 21 months of supporting traditional midwives on their own terms. Two-sided 
Table 5 Sensitivity analyses incorporating levels of fidelity to the intervention

\begin{tabular}{|c|c|c|c|c|}
\hline & \multicolumn{2}{|c|}{$\begin{array}{l}\text { Absolut event rate } \\
\text { (n) }\end{array}$} & \multirow[t]{2}{*}{$\begin{array}{l}\mathrm{RD} \\
95 \% \mathrm{Cla}^{\mathrm{a}}\end{array}$} & \multirow[t]{2}{*}{$\begin{array}{l}\text { OR } \\
95 \% \mathrm{Cl}^{\text {b }}\end{array}$} \\
\hline & Intervention & Control & & \\
\hline Protocol-adherent communities vs control communities & (cluster $n=13$ ) & (cluster $n=40$ ) & & \\
\hline Total traditional childbirths ${ }^{c d}$ & $\begin{array}{l}0.34 \\
(40 / 119)\end{array}$ & $\begin{array}{l}0.11 \\
(48 / 457)\end{array}$ & $\begin{array}{l}0.23 \\
0.09 \text { to } 0.38\end{array}$ & $\begin{array}{l}8.67 \\
2.70 \text { to } 27.8\end{array}$ \\
\hline Unattended childbirths & $\begin{array}{l}0.03 \\
(4 / 117)\end{array}$ & $\begin{array}{l}0.06 \\
(26 / 456)\end{array}$ & $\begin{array}{l}-0.02 \\
-0.08 \text { to } 0.03\end{array}$ & $\begin{array}{l}0.69 \\
0.18 \text { to } 2.72\end{array}$ \\
\hline Perinatal mortality & $\begin{array}{l}0.03 \\
(3 / 122)\end{array}$ & $\begin{array}{l}0.03 \\
(16 / 468)\end{array}$ & $\begin{array}{l}-0.02 \\
-0.06 \text { to } 0.03\end{array}$ & $\begin{array}{l}0.66 \\
0.25 \text { to } 1.77\end{array}$ \\
\hline Neonatal complications & $\begin{array}{l}0.06 \\
(7 / 118)\end{array}$ & $\begin{array}{l}0.09 \\
(39 / 456)\end{array}$ & $\begin{array}{l}-0.03 \\
-0.10 \text { to } 0.04\end{array}$ & $\begin{array}{l}0.61 \\
0.25 \text { to } 1.71\end{array}$ \\
\hline Childbirth complications $^{c}$ & $\begin{array}{l}0.03 \\
(3 / 119)\end{array}$ & $\begin{array}{l}0.08 \\
(35 / 456)\end{array}$ & $\begin{array}{l}-0.05 \\
-0.08 \text { to }-0.02\end{array}$ & $\begin{array}{l}0.35 \\
0.14 \text { to } 0.92\end{array}$ \\
\hline As treated & (cluster $n=22$ ) & (cluster $n=40$ ) & & \\
\hline $\begin{array}{l}\text { Childbirth complications } \\
\text { Fear or good performance vs control }{ }^{c}\end{array}$ & $\begin{array}{l}0.03 \\
(6 / 199)\end{array}$ & $\begin{array}{l}0.08 \\
(35 / 456) \\
\text { (cluster } n=58)\end{array}$ & $\begin{array}{l}-0.05 \\
-0.08 \text { to }-0.01\end{array}$ & $\begin{array}{l}0.37 \\
0.15 \text { to } 0.90\end{array}$ \\
\hline $\begin{array}{l}\text { Childbirth complications } \\
\text { Fear or good vs control and poor performance }\end{array}$ & $\begin{array}{l}0.03 \\
(6 / 199)\end{array}$ & $\begin{array}{l}0.07 \\
(48 / 650)\end{array}$ & $\begin{array}{l}-0.04 \\
-0.08 \text { to }-0.01\end{array}$ & $\begin{array}{l}0.39 \\
0.16 \text { to } 0.93\end{array}$ \\
\hline Instrumental variable & (cluster $n=40$ ) & (cluster $n=40$ ) & & \\
\hline Perinatal mortality & $\begin{array}{l}0.03 \\
(3 / 122)\end{array}$ & $\begin{array}{l}0.03 \\
(16 / 468)\end{array}$ & $\begin{array}{l}-0.03 \\
-0.12 \text { to } 0.06\end{array}$ & \\
\hline Neonatal complications & $\begin{array}{l}0.06 \\
(7 / 118)\end{array}$ & $\begin{array}{l}0.09 \\
(39 / 456)\end{array}$ & $\begin{array}{l}-0.11 \\
-0.25 \text { to } 0.04\end{array}$ & \\
\hline Childbirth complications $^{c}$ & $\begin{array}{l}0.03 \\
(3 / 119)\end{array}$ & $\begin{array}{l}0.08 \\
(35 / 456)\end{array}$ & $\begin{array}{l}-0.09 \\
-0.18 \text { to } 0.00\end{array}$ & \\
\hline
\end{tabular}

$R D$ risk difference, $O R$ odds ratio

${ }^{a}$ Baseline-adjusted cluster-level analysis using t-test as presented by Campbell, 2014

${ }^{b} \mathrm{OR}$ and confidence intervals calculated with a GLMM using Ime4 package in R

' Significant differences at the $5 \%$ level

$d$ at home, with traditional midwife and family and in preferred vertical position

95\% confidence intervals excluded parity for childbirth complications, and indicated non-inferiority limits of 1 and $2 \%$ for neonatal complications and perinatal deaths, respectively. Consistent results for ITT and non-ITT analyses confirmed lower rates of primary outcomes in those communities with higher fidelity intervention.

Non-inferiority trials are intended to show the intervention is not worse than the existing option on the premise that it has other advantages [33]. Supporting traditional midwives on their own terms improved cultural safety by increasing traditional childbirths and, in communities where there was higher intervention fidelity, lowering rates of unattended births. The intervention improved handling of the placenta in institutional births, to accommodate traditional norms. Other aspects of cultural safety in Western facilities failed to improve.

For almost a century [50], engagement of traditional midwives has focused on their being re-trained and used as auxiliary health workers to extend the provision of Western health services [3, 51-53]. Apart from our pilot trial [27], we could not identify any published trial of supporting traditional midwifery on its own terms.

Several studies report positive effects on peri-neonatal morbidity and mortality from working with traditional midwives [10, 11, 13-15, 19, 54], some exploring costeffective results [21, 22]. Traditional midwives in Guerrero described complex knowledge of risk factors and preventive practices, albeit framed in the terms of their traditional culture [55]. In a similar context in Guatemala, Austad [56] reported improvements in management of complications associated with support of obstetric care navigators, a role that intercultural brokers in Guerrero offered in coordination with the traditional midwives and their apprentices [57].

For many Indigenous communities, place of birth and involvement with childbirth rituals are connected to identity, culture and territories, and even some roles in governance $[58,59]$. In our study, women who gave birth at home with a traditional midwife were less likely to intend to have an institutional childbirth in the future. 
Preference for home births in this region is closely linked to cultural values, and mistreatment or disrespect shown to Indigenous women in health institutions reinforces this preference $[26,60,61]$. Beyond Indigenous communities, mistreatment [62], disrespect [63], and violence against women [64] during childbirth have gained increasing attention $[65,66]$. Despite the controversy surrounding the safety of home births [67-69], our study supports the argument that safe birth in places like Guerrero "needs a fully integrated comprehensive maternity care network that is supportive and responsive" [70]. In a context like ours, where ildigenous women mostly give birth at home [26], informed and principled interaction of the official health system with traditional midwives can pave the way for respectful and women-centred care.

Notwithstanding the well-documented benefits of modern obstetric care for the medical safety of mothers and children, there are also unintended side effects and iatrogenic illnesses [71, 72]. There are some procedures that women consider injurious but providers do not $[63,65]$. Understanding what Indigenous women consider harmful practices requires interaction and mutual learning [30]. Rituals associated with handling of the placenta, for example, have profound implications for cultural identity in these communities and set the path for a healthy life of the child. Baths with cold water in the postpartum period, on the other hand, are regarded as violence, a source of coldness of the womb, and a cause of poor maternal health [55]. Promotion of cultural safety in Western institutions requires additional efforts and is an ongoing challenge for medical education.

\section{Limitations and strengths}

Sample size is a common limitation of research with small and remote Indigenous communities even including, as we did, all the women in the community. Accumulating numbers of events by increasing the duration of the study depends on availability of funding. We reported on 872 completed pregnancies and some additional months of follow up would have allowed us to include in the analysis the outcomes of several hundred women who were still pregnant at the moment of the final survey. The cluster design avoided contamination that would occur if intervention traditional midwives attended women in control communities [73]. The clustered design reduced the power of the study, making it harder to demonstrate non-inferiority. The baseline survey in 2015 revealed intervention women had important differences from control women in their language, schooling and support during childbirth. The direction of the differences would have us expect worse maternal health outcomes in intervention communities, which could lead to underestimation of a positive effect of the intervention.
The difficult field conditions affected measurement of gender violence, a key ripple effect in the pilot study. Interviewers had to administer these questions, for security reasons, under conditions where the respondent could be seen and possibly overheard. We observed similar difficulties and attendant limits to interpretation earlier in Guerrero [74] and in Pakistan [75].

Knowledge of intervention status could have affected some secondary outcomes (for example, intention of future home-based childbirths). The main outcome indicators (non-inferiority for perinatal mortality, neonatal and serious childbirth complications) and other secondary outcomes would be less susceptible to this bias.

The study benefitted from decades of institutional commitment and experience of CIET researchers that cannot be assumed in other contexts. This community engagement generated the co-designed intervention. During the trial, the researchers also generated institutional support in government facilities, and established a favourable environment to discuss results with local authorities.

\section{Conclusions}

Supporting traditional midwives on their own terms can increase cultural safety without worsening birth outcomes. The small size of Indigenous populations and restricted funding for the intervention limits interpretation of this potentially important finding. Further research needs to explore the added benefit of increased collaboration with Western stakeholders. Traditional midwifery could contribute to safer birth among Indigenous communities if, instead of attempting to replace traditional practices, health authorities promoted intercultural dialogue.

\begin{abstract}
Abbreviations
Cl: Confidence interval; CIET: Centro de Investigación de Enfermedades Tropicales; CINAHL: Cumulative Index to Nursing and Allied Health Literature; CONSORT: Consolidated Standards of Reporting Trials; GLMM: Generalised linear mixed model; ICC: Intra-cluster correlation coefficient; ITT: Intention to treat; LILACS: Latin American and Caribbean Health Sciences Literature; OR: Odds ratio; RCT: Randomised controlled trial; RD: Risk difference.
\end{abstract}

\section{Supplementary Information}

The online version contains supplementary material available at https://doi. org/10.1186/s12884-021-04344-w.

Additional file 1. Evaluation of the implementation of the intervention and baseline characteristics. Evaluation of each of the components of the intervention according to the participating traditional midwives and baseline characteristics of each community.

Additional file 2. Comparison of groups as treated using GLMMs. The table shows the comparison of groups as treat using OR and 95\% confidence intervals. 


\begin{abstract}
Acknowledgements
Traditional midwives in Guerrero, the group of intercultural brokers and CIET team generously worked to implement the trial moved by a genuine concern with mother and child health. The Colombian team at the Centro de Estudios Médicos Interculturales shared its experience in intercultural dialogue with Indigenous communities. The members of Participatory Research at McGill kindly discussed early versions of this work.
\end{abstract}

\section{Authors' contributions}

IS and NA conducted the statistical analysis and drafted the manuscript. IS conducted the qualitative evaluation of intervention with traditional midwives. SP, FS, JL managed the trial fieldwork and coordinated data collection. AJG and NM supported the implementation as field coordinators. GZ contributed to designing the training program for intercultural brokers and advised the intercultural approach. AC supported the analysis and the final drafting of the article reporting the results. All authors read, contributed to, and approved the final manuscript.

\section{Funding}

The pilot received support from UBS Optimus Foundation. The National Council of Science and Technology of Mexico funded the BMx2 randomised controlled trial (PDCPN-2013-214858). The Quebec Population Health Research Network and the Faculty of Medicine of McGill University provided support for fieldwork. CeiBA Foundation and the Center of Intercultural Medical Studies in Colombia, and the Fonds de Recherche du Québec Santé (255253) supported the analysis of the randomised controlled trial. The design, management, analysis, and reporting of the data are entirely independent from all sources of funding.

\section{Availability of data and materials}

The datasets used and/or analysed during the current study are available from the corresponding author on reasonable request. According to the agreements with participating communities, to ensure the protection of participants and governance of data, before the information can be shared, the requester will need to present a plan for data analysis. Also, the requester will need to complete the procedure for ethical approval of the secondary analysis in accordance with the procedures defined by the Ethics Board of the Universidad Autónoma de Guerrero.

\section{Declarations}

\section{Ethics approval and consent to participate}

The methods and procedures received prospective ethical approval from all participating communities (2015), the Ethics Committee of the Centro de Investigación de Enfermedades Tropicales of the Universidad Autónoma de Guerrero (reference 2013-014), and McGill's Faculty of Medicine Institutional Review Board (reference A06-B28-17B). All methods were performed in accordance with the relevant guidelines and regulations. We adopted the ethical principles for medical research in Indigenous communities proposed by the Research Group on Traditional Health Systems [36]. These principles incorporate the International Ethical Guidelines for Health-related Research Involving Humans (CIOMS, 2012 and maintain compliance with the version of 2016), Declaration of Helsinki (2013) and the Canadian Tri-Council Policy Statement: Ethical Conduct for Research Involving Humans chapter 9. We obtained informed consent from Indigenous mothers during data collection.

\section{Consent for publication}

Not applicable.

\section{Competing interests}

The authors declare that they have no competing interests.

\section{Author details}

${ }^{1}$ CIET-Participatory Research at McGill, Faculty of Medicine and Health Sciences, Department of Family Medicine, McGill University, 5858 Chemin de la Côte des Neiges 3rd floor, Montreal, QC H3S 1Z1, Canada. ${ }^{2}$ Grupo de Estudios en Sistemas Tradicionales de Salud, Escuela de Medicina y Ciencias de la Salud, Universidad del Rosario, Bogotá, Colombia. ${ }^{3}$ Centro de Investigación de Enfermedades Tropicales, Universidad Autónoma de Guerrero, Acapulco, Mexico.
Received: 30 March 2021 Accepted: 10 December 2021

Published online: 17 January 2022

\section{References}

1. Harrison KA. Are traditional birth attendants good for improving maternal and perinatal health? No. BMJ. 2011;342:d3308. https://doi.org/10.1136/ bmj.d3308.

2. Ana J. Are traditional birth attendants good for improving maternal and perinatal health? Yes. BMJ. 2011;342:d3310. https://doi.org/10.1136/bmj. d3310.

3. Gill CJ, Hamer DH, Knapp AB. Dispelling the myths surrounding traditional birth attendants. BMJ. 2011;343:d4481. https://doi.org/10.1136/ bmj.d4481.

4. International Labour Organization. International standard classification of occupations 2008 (ISCO-08): structure, group definitions and correspondence tables. Geneve: International Labour Office; 2012. http://ebookcentr al.proquest.com/lib/mcgill/detail.action?doclD=991922. Accessed 10 May 2020

5. Bergström S, Goodburn E. The role of traditional birth attendants in the reduction of maternal mortality. In: Safe motherhood strategies: a review of the evidence. Antwerp: ITG Press; 2001. p. 77-96.

6. Bullough C, Meda N, Makowiecka K, Ronsmans C, Achadi EL, Hussein J. Review: current strategies for the reduction of maternal mortality. BJOG An Int J Obstet Gynaecol. 2005;112:1180-8. https://doi.org/10.1111/j. 1471-0528.2005.00718.x.

7. Sibley LM, Sipe TA, Koblinsky M. Does traditional birth attendant training increase use of antenatal care? A review of the evidence. J Midwifery Womens Health. 2004:49:298-305.

8. Sibley L, Sipe TA, Koblinsky M. Does traditional birth attendant training improve referral of women with obstetric complications: a review of the evidence. Soc Sci Med. 2004;59:1757-68.

9. Kruske S, Barclay L. Effect of shifting policies on traditional birth attendant training. J Midwifery Womens Health. 2004;49:306-11.

10. Sibley LM, Sipe TA, Barry D. Traditional birth attendant training for improving health behaviours and pregnancy outcomes. Cochrane Database Syst Rev. 2012:CD005460. https://doi.org/10.1002/14651858.CD005460.pub3.

11. Sibley L, Sipe TA. What can a meta-analysis tell us about traditional birth attendant training and pregnancy outcomes? Midwifery. 2004;20:51-60.

12. Wilson A, Gallos ID, Plana N, Lissauer D, Khan KS, Zamora J, et al. Effectiveness of strategies incorporating training and support of traditional birth attendants on perinatal and maternal mortality: meta-analysis. BMJ $\mathrm{Br}$ Med J. 2012;344:16

13. Lassi ZS, Das JK, Salam RA, Bhutta ZA. Evidence from community level inputs to improve quality of care for maternal and newborn health: interventions and findings. Reprod Health. 2014;11(Suppl 2):S2. https:// doi.org/10.1186/1742-4755-11-S2-S2.

14. Wilson A, Gallos ID, Plana N, Lissauer D, Khan KS, Zamora J, et al. Effectiveness of strategies incorporating training and support of traditional birth attendants on perinatal and maternal mortality: meta-analysis. BMJ. 2011;343:d7102.

15. Darmstadt GL, Lee ACC, Cousens S, Sibley L, Bhutta ZA, Donnay F, et al. 60 million non-facility births: who can deliver in community settings to reduce intrapartum-related deaths? Int J Gynecol Obstet. 2009;107(suppl):S89-112.

16. Lassi ZS, Middleton PF, Bhutta ZA, Crowther C. Strategies for improving health care seeking for maternal and newborn illnesses in low- and middle-income countries: a systematic review and meta-analysis. Glob Health Action. 2016;9:31408.

17. Carlo WA, Goudar SS, Jehan I, Chomba E, Tshefu A, Garces A, et al. Newborn-care training and perinatal mortality in developing countries. $N$ Engl J Med. 2010;362:614-23. https://doi.org/10.1056/NEJMsa0806033.

18. Gill CJ, Phiri-Mazala G, Guerina NG, Kasimba J, Mulenga C, MacLeod WB, et al. Effect of training traditional birth attendants on neonatal mortality (Lufwanyama neonatal survival project): randomised controlled study. BMJ. 2011;342:d346. https://doi.org/10.1136/bmj.d346.

19. Manasyan A, Chomba E, Moore J, Wallace D, McClure EM, Koso-Thomas $\mathrm{M}$, et al. Association between birth attendant type and delivery site and perinatal outcomes. Int J Gynecol Obstet. 2019;145:187-92. https://doi. org/10.1002/ijgo.12786. 
20. Kidney E, Winter HR, Khan KS, Gülmezoglu AM, Meads CA, Deeks JJ, et al. Systematic review of effect of community-level interventions to reduce maternal mortality. BMC Pregnancy Childbirth. 2009;9:2. https://doi.org/ 10.1186/1471-2393-9-2.

21. Mangham-Jefferies L, Pitt C, Cousens S, Mills A, Schellenberg J. Cost-effectiveness of strategies to improve the utilization and provision of maternal and newborn health care in low-income and lower-middle-income countries: a systematic review. BMC Pregnancy Childbirth. 2014;14:243.

22. Sabin L, Knapp A, MacLeod W, Phiri-Mazala G, Kasimba J, Hamer D, et al. Costs and cost-effectiveness of training traditional birth attendants to reduce neonatal mortality in the Lufwanyama Neonatal Survival study (LUNESP). PLoS One. 2012;7:e35560.

23. Instituto Nacional de Estadística y Geografía de México. Mortalidad General. https://www.inegi.org.mx/sistemas/olap/Proyectos/bd/continuas/ mortalidad/MortalidadGeneral.asp. Accessed 28 Mar 2019.

24. Observatorio de Mortalidad Materna de México. Boletín de mortalidad materna. Semana epidemiológica 52 información actualizada al 31 de diciembre de 2017. http://www.omm.org.mx/images/stories/Docum entosgrandes/BOLETIN_52_2017_COMPLETO.pdf. Accessed 10 Jun 2018.

25. Pisanty-Alatorre J. Inequidades en la mortalidad materna en México: un análisis de la desigualdad a escala subestatal. Salud Publica Mex. 2017:59:639. https://doi.org/10.21149/8788.

26. de Jesús-García A, Paredes-Solís S, Valtierra-Gil G, los Santos FRS, SánchezGervacio BM, Ledogar RJ, et al. Associations with perineal trauma during childbirth at home and in health facilities in indigenous municipalities in southern Mexico: a cross-sectional cluster survey. BMC Pregnancy Childbirth. 2018;18:198. https://doi.org/10.1186/s12884-018-1836-8.

27. Sarmiento I, Paredes-Solís S, Andersson N, Cockcroft A. Safe birth and cultural safety in southern Mexico: study protocol for a randomised controlled trial. Trials. 2018;19:354. https://doi.org/10.1186/ s13063-018-2712-6.

28. Dietz G. Interculturality. In: Callan H, editor. The international encyclopedia of anthropology. Oxford: Wiley; 2018. p. 1-19. https://doi.org/10.1002/ 9781118924396.wbiea1629.

29. Argueta Villamar A, Pérez Ruiz ML. Los Saberes tradicionales y los desafíos para el Diálogo de conocimientos. Desenvolv e Meio Ambient. 2019;50. https://doi.org/10.5380/dma.v50i0.65438.

30. Sarmiento I, Zuluaga G, Paredes-Solís S, Chomat AM, Loutfi D, Cockcroft A, et al. Bridging Western and indigenous knowledge through intercultural dialogue: lessons from participatory research in Mexico. BMJ Glob Health. 2020;5:e002488. https://doi.org/10.1136/bmjgh-2020-002488.

31. Moher D, Hopewell S, Schulz KF, Montori V, Gotzsche PC, Devereaux PJ, et al. CONSORT 2010 explanation and elaboration: updated guidelines for reporting parallel group randomised trials. BMJ. 2010;340:c869. https:// doi.org/10.1136/bmj.c869.

32. Campbell MK, Piaggio G, Elbourne DR, Altman DG. Consort 2010 statement: extension to cluster randomised trials. BMJ. 2012;345:e5661. https://doi.org/10.1136/bmj.e5661.

33. Piaggio G, Elbourne DR, Pocock SJ, Evans SJW, Altman DG, CONSORT Group for the. Reporting of noninferiority and equivalence randomized trials. JAMA. 2012;308:2594. https://doi.org/10.1001/jama.2012.87802.

34. Hopewell S, Clarke M, Moher D, Wager E, Middleton P, Altman DG, et al. CONSORT for reporting randomized controlled trials in journal and conference abstracts: explanation and elaboration. PLoS Med. 2008;5:e20. https://doi.org/10.1371/journal.pmed.0050020.

35. Canadian Institutes of Health Research, Natural Sciences and Engineering Research Council of Canada, Social Sciences and Humanities Research Council of Canada. TCPS 2 chapter 9. In: Tri-council policy statement: ethical conduct for research involving humans; 2014. p. 109-38. https:// ethics.gc.ca/eng/tcps2-eptc2_2018_chapter9-chapitre9.html. Accessed 18 Jan 2021.

36. Zuluaga G. Una ética para la investigación médica con comunidades indígenas. In: Vélez A, Ruiz A, Torres M, editors. Retos y dilemas de los comités de ética en investigación. Colección. Bogotá: Editorial Universidad del Rosario; 2013. p. 259-81. http://media.wix.com/ugd/cb47c9_d7903 40d497847e58f5505518c122b24.pdf. Accessed 30 Apr 2014.

37. Meneses S, Pelcastre B, Vega M. Maternal mortality and the coverage, availability of resources, and access to women's health services in three indigenous regions of Mexico: Guerrero Mountains, Tarahumara Sierra, and Nayar. In: Schwartz DA, editor. Maternal death and pregnancy-related morbidity among indigenous women of Mexico and Central America. Cham: Springer International Publishing; 2018. p. 169-88.

38. Reich NG, Myers JA, Obeng D, Milstone AM, Perl TM. Empirical power and sample size calculations for cluster-randomized and cluster-randomized crossover studies. PLoS One. 2012;7:e35564. https://doi.org/10.1371/ journal.pone.0035564.

39. Kruschke J. Doing Bayesian data analysis: a tutorial introduction with $\mathrm{R}$; 2014. p. 776.

40. Campbell MJ, Walters SJ. How to design, analyse and report cluster randomised trials in medicine and health related research. Hoboken: Wiley; 2014.

41. Rafi Z, Greenland S. Semantic and cognitive tools to aid statistical science: replace confidence and significance by compatibility and surprise. BMC Med Res Methodol. 2020;20:244. https://doi.org/10.1186/ s12874-020-01105-9.

42. Andersson N, Mitchell S. Epidemiological geomatics in evaluation of mine risk education in Afghanistan: introducing population weighted raster maps. Int J Health Geogr. 2006;5:1. https://doi.org/10.1186/ 1476-072X-5-1.

43. Campbell MK, Mollison J, Steen N, Grimshaw JM, Eccles M. Analysis of cluster randomized trials in primary care: a practical approach. Fam Pract. 2000;17:192-6.

44. Sommet N, Morselli D. Keep calm and learn multilevel logistic modeling: a simplified three-step procedure using stata, R, Mplus, and SPSS. Int Rev Soc Psychol. 2017;30:203-18. https://doi.org/10.5334/irsp.90.

45. Therneau T, Atkinson B, Ripley B. Package'rpart'; 2019. p. 34. https://cran.rproject.org/package=rpart

46. Shrier I, Steele RJ, Verhagen E, Herbert R, Riddell CA, Kaufman JS. Beyond intention to treat: what is the right question? Clin Trials J Soc Clin Trials. 2014;11:28-37. https://doi.org/10.1177/1740774513504151.

47. Agbla SC, DiazOrdaz K. Reporting non-adherence in cluster randomised trials: a systematic review. Clin Trials. 2018;15:294-304. https://doi.org/10. $1177 / 1740774518761666$.

48. Agbla SC, De Stavola B, DiazOrdaz K. Estimating cluster-level local average treatment effects in cluster randomised trials with non-adherence. Stat Methods Med Res. 2020;29:911-33. https://doi.org/10.1177/0962280219 849613.

49. Huang FL. Using instrumental variable estimation to evaluate randomized experiments with imperfect compliance. Pract Assess Res Eval. 2018;23:1-8.

50. Leedam E. Traditional birth attendants. Int J Gynecol Obstet. 1985;23:24974. https://doi.org/10.1186/1471-2458-10-570.

51. De Brouwere V, Tonglet RR, Van Lerberghe WW. Strategies for reducing maternal mortality in developing countries: what can we learn from the history of the industrialized west? Trop Med Int Health. 1998;3:771-82. https://doi.org/10.1046/j.1365-3156.1998.00310.x.

52. Pigg SL. Authority in translation. Finding, knowing, naming, and training "traditional birth attendants" in Nepal. In: Davis-Floyd R, Sargent CF, editors. Childbirth and authoritative knowledge: cross-cultural perspectives. Berkeley: University of California Press; 1997. p. 233-62.

53. World Health Organization. Working with individuals, families and communities to improve maternal and newborn health. Geneva: World Health Organization; 2010. https://www.who.int/maternal_child_adole scent/documents/who_fch_rhr_0311/en/. Accessed 5 Apr 2019

54. Carlo WA, McClure EM, Chomba E, Chakraborty H, Hartwell T, Harris H, et al. Newborn care training of midwives and neonatal and perinatal mortality rates in a developing country. Pediatrics. 2010;126:e1064-71. https://doi.org/10.1542/peds.2009-3464.

55. Sarmiento I, Paredes-Solís S, Loutfi D, Dion A, Cockcroft A, Andersson N. Fuzzy cognitive mapping and soft models of indigenous knowledge on maternal health in Guerrero, Mexico. BMC Med Res Methodol. 2020;20:125. https://doi.org/10.1186/s12874-020-00998-w.

56. Austad K, Juarez M, Shryer H, Moratoya C, Rohloff P. Obstetric care navigation: results of a quality improvement project to provide accompaniment to women for facility-based maternity care in rural Guatemala. BMJ Qual Saf. 2020;29:169-78. https://doi.org/10.1136/bmjqs-2019-009524.

57. Paredes-Solís S, de Jesús-García A, Valtierra-Gil G, Gasga D, LegorretaSoberanis J. Percepción de los cambios producidos por la enseñanza de parteras tradicionales experimentadas de Xochistlahuaca, Guerrero. In: Freyermuth G, Vega M, Tinoco A, Gil G, editors. Los caminos para parir 
en México en el siglo xxi: experiencias de investigación, vinculación, formación y comunicación. Ciudad de México: M; 2018. p. 194-203.

58. Berry NS. Kaqchikel midwives, home births, and emergency obstetric referrals in Guatemala: contextualizing the choice to stay at home. Soc Sci Med. 2006;62:1958-69.

59. Jordan B. Birth in four cultures: a crosscultural investigation of childbirth in Yucatan, Holland, Sweden, and the United States. 4th ed. Long Grove: Waveland Press; 1993.

60. Mills $L$. The limits of trust: the millennium development goals, maternal health, and health policy in Mexico. Montreal: McGill-Queen's University Press; 2017.

61. Peca E, Sandberg J. Modeling the relationship between women's perceptions and future intention to use institutional maternity care in the Western highlands of Guatemala. Reprod Health. 2018;15:9. https://doi. org/10.1186/s12978-017-0448-5.

62. Rosen HE, Lynam PF, Carr C, Reis V, Ricca J, Bazant ES, et al. Direct observation of respectful maternity care in five countries: a cross-sectional study of health facilities in east and southern Africa. BMC Pregnancy Childbirth. 2015;15:306. https://doi.org/10.1186/s12884-015-0728-4.

63. Freedman LP, Ramsey K, Abuya T, Bellows B, Ndwiga C, Warren CE, et al. Defining disrespect and abuse of women in childbirth: a research, policy and rights agenda. Bull World Health Organ. 2014;92:915-7.

64. Zacher DL. Obstetrics in a time of violence: Mexican midwives critique routine hospital practices. Med Anthropol Q. 2015;29:437-54. https://doi. org/10.1111/maq.12174.

65. Freedman LP, Kruk ME. Disrespect and abuse of women in childbirth: challenging the global quality and accountability agendas. Lancet. 2014;384:e42-4

66. Bohren MA, Vogel JP, Hunter EC, Lutsiv O, Makh SK, Souza JP, et al. The mistreatment of women during childbirth in health facilities globally: a mixed-methods systematic review. PLoS Med. 2015;12:e1001847. https:// doi.org/10.1371/journal.pmed.1001847.

67. Janssen PA, Saxell L, Page LA, Klein MC, Liston RM, Lee SK. Outcomes of planned home birth with registered midwife versus planned hospital birth with midwife or physician. CMAJ. 2009;181:377-83. https://doi.org/ 10.1503/cmaj.081869.

68. Wax JR, Lucas FL, Lamont M, Pinette MG, Cartin A, Blackstone J. Maternal and newborn outcomes in planned home birth vs planned hospital births: a metaanalysis. Am J Obstet Gynecol. 2010;203(243):e1-8. https:// doi.org/10.1016/j.ajog.2010.05.028.

69. Olsen O. Meta-analysis of the safety of home birth. Birth. 2008;24:4-13. https://doi.org/10.1111/j.1523-536X.1997.00004.pp.x.

70. Walker JJ. Planned home birth. Best Pract Res Clin Obstet Gynaecol. 2017:43:76-86. https://doi.org/10.1016/j.bpobgyn.2017.06.001.

71. Kennedy HP, Cheyney M, Dahlen HG, Downe S, Foureur MJ, Homer CSE, et al. Asking different questions: a call to action for research to improve the quality of care for every woman, every child. Birth. 2018;45:222-31.

72. Miller S, Abalos E, Chamillar M, Ciapponi A, Colaci D, Comande D, et al. Beyond "too little, too late and too much, too soon": a pathway towards evidence-based, respectful maternaity care worldwide. Lancet. 2016;388:2176-92.

73. Andersson N, Lamothe G. Clustering and meso-level variables in crosssectional surveys: an example of food aid during the Bosnian crisis. BMC Health Serv Res. 2011;11(Suppl 2):S15. https://doi.org/10.1186/ 1472-6963-11-S2-S15.

74. Paredes-Solís S, Villegas-Arrizón A, Meneses-Rentería A, Rodríguez-Ramos I, Reyes-De Jesús L, Andersson N. Violencia física intrafamiliar contra la embarazada: un estudio con base poblacional en Ometepec, Guerrero, México. Salud Publica Mex. 2005;47:335-41 http://www.scielo.org.mx/ scielo.php?script=sci_arttext\&pid=S0036-36342005000500003\&nrm= iso. Accessed 17 Feb 2020

75. Mhatre S, Andersson N, Ansari NM, Omer K. Access to justice for women of Karachi. 2002. https://www.ciet.org/wp-content/blogs.dir/20/files/ 2019/10/2006224174127.pdf. Accessed 17 Feb 2020.

\section{Publisher's Note}

Springer Nature remains neutral with regard to jurisdictional claims in published maps and institutional affiliations.

Ready to submit your research? Choose BMC and benefit from:

- fast, convenient online submission

- thorough peer review by experienced researchers in your field

- rapid publication on acceptance

- support for research data, including large and complex data types

- gold Open Access which fosters wider collaboration and increased citations

- maximum visibility for your research: over $100 \mathrm{M}$ website views per year

At BMC, research is always in progress.

Learn more biomedcentral.com/submissions 